\title{
Knowing as Intervention: Reflections on the Application of Systems Ideas
}

\author{
Norma Romm ${ }^{1}$ \\ Received November 15, 1993; revised March 18, 1994

\begin{abstract}
The relation between theory and practice is explored in this paper with respect to an examination of various systems approaches. It is argued that the moment of "knowing" already contains practical implications in that "comprehension" gears practice in certain directions. Practice/application can fulfill the demands of theory through the operation of a self-fulfilling prophecy effect. The way in which theoretical conceptions of systems researchers may constrain practice is explored with reference to the work of Beer, Checkland and Scholes, and Ulrich. In the course of this exploration, alternative views of the way in which viable systems diagnosis, soft systems methodology, and critical systems heuristics may be utilised, are offered.
\end{abstract}

KEY WORDS: theory; practice; viable systems diagnosis; soft systems methodology; critical systems heuristics; narrative construction; opposition/confrontation; choice-making.

\section{INTRODUCTION}

This paper puts forward the suggestion that the process of attempting to "know" about the social world already is an intervention in that world which may come to shape its constitution. As soon as systems researchers employ methods of intervention which they believe are based on "sound theoretical knowledge," they direct action in a particular way-they contribute to the shaping of participants' self-understandings and their conception of options for action. Knowing is thus an intervention which makes real certain possibilities in "the situation." This argument presupposes that we recognise-as most systems researchers dothat in the social world "actors" may "make use of" knowledge as formulated by the researcher. But this argument goes further, suggesting that once we recognise this, we also have to take account of the self-fulfilling prophecy effect that our knowing/understanding might have. The argument in this paper is that since we can never know the degree to which our perceptions of a "situation"

'Centre for Systems Studies, Department of Management Systems and Sciences, University of Hull, Hull, HU6 7RX United Kingdom. 
are a product of our constructions/viewpoint, we have the responsibility to consider the possible impact that these constructions may have when they "enter" the world of the social participants. In order to pursue this argument, the paper addresses and explores various systems methodologies from the point of view of their epistemological orientation.

The paper is structured by considering the way in which certain proponents' use of systemic approaches for intervening in the social world can be subjected to (epistemological) reconsideration. This is done by critically addressing in turn Stafford Beer's approach to viable systems diagnosis, Peter Checkland and Jim Scholes' soft systems approach, and Werner Ulrich's critical systems heuristics.

The argument proposed is that these theorists' justifications for intervention often do not account for the way in which "theoretical understanding" already may constrain "action" to follow certain paths. How can the quality of our "knowledge" be enhanced so that such constraining effects of intervention are mitigated? The paper suggests that "knowledge" has to be treated in such a way that it invites ongoing discursive appropriation-by "lay" actors in the social world (lay theorists); by other theorists (professional theorists); and, indeed, by self-reflection on the part of the theorist advancing the initial constructions. In pursuing this argument, the paper draws upon and elaborates specific alternative conceptions of the relevance of "viable systems diagnosis" and "soft systems methodology" - namely, the conceptions provided by Espejo and Harnden and Davies, respectively, and it also reconsiders and reviews some of the suggestions advanced by Ulrich in relation to the use of critical systems heuristics. While it takes up many of Ulrich's (epistemological) arguments, it also shows that at times Ulrich seems to slip into offering theoretical constructions which appear unnegotiable.

The paper concludes by suggesting that "theoretical insights" advanced by people should be regarded as constructions (narratives) which may shift as they encounter confrontation with other positions. This proposal ties in with certain postmodern arguments regarding the ongoing de- and reconstruction of "stories" about the world. But it still allows us to define the quality of "better" stories (or rather the better use of stories by theorists/actors) by considering the capacity of the story to encounter opposition. This capacity, it is argued, is located in the awareness of theorists of the fragility of all theoretical positions, coupled with a propensity to encounter "bad news" for their stance.

The argument is presented by examining the stances of Beer, Checkland and Scholes, and Ulrich, reviewing their self-understandings of the "theoretical basis" of their approaches.

\section{BEER'S ARGUMENT}

Beer is often regarded as being one of the key proponents of a "hard" approach which considers that systems in the social world can be analysed in 
the same way as, and compared with, those in the natural world. He himself refers to the similarity of natural and social scientific endeavours to discover the existence of laws and principles which apply to the natural and social worlds alike (1985, p. ix). He argues that cybernetics, as the "science of effective organisation," is aimed at identifying laws or principles of control "that apply to all kinds of complex systems, whether animate or inanimate, technical or societary" (1985, p. ix). ${ }^{2}$ Beer sees the relationship between the "knowledge" which he advances (through the use of a scientific approach) and interventions in the social world as follows: His cybemetics-as the science of effective organisation-provides a tool whereby those who wish to render their organisation more viable may act in terms of an account of the dysfunctionalities in the organisation. He suggests that his book "diagnosing the system for organisation" will tell you "how to design an organisational structure-and how to diagnose a faulty one" ( 1985, p. iii). He argues that "survival minded people", would do well to consider his suggestions concerning the redesign of any form of societal organisation so as to alleviate organisational dysfunctions. Beer is concerned that many people behave in society without due consideration for the principles of viability which render possible the survival of organisational systems. As he states,

It is a fascinating feature of contemporary society that the participants . . . seem willing to pursue selfish interest to the point where the viable system in which they have a profound stake, as employees, as needy consumers, as regional inhabitants, is actually rendered viable no longer. $(1985, \mathrm{pp} .12,13)$

Beer claims that his statements about the "laws" of the viable system (1985, p. $\mathrm{x}$ ) are grounded with reference to the (real) laws of viability - he hopes to have offered statements which are true in the sense of referring to really existent laws. He suggests that the statements which he provides are "intuitively obviouslike most truths" (1985, p. iii). He believes that his Viable System Model (VSM) offers a (more or less simplified) presentation of a viable system which is designed to take account of the laws of viability-such a model should be useful to the extent that it helps people to generate viable systems. The model of a viable system is useful in helping people to redesign any particular system (1985, p. 2).

Beer argues that one of the justifications for the "validity" of his pronouncements regarding viable structures is the fact that his model has indeed proved useful for those wishing to generate viability in their organisation. By pointing to "Some Applications of the Viable System Model"' (1989, pp. 34-

\footnotetext{
${ }^{2}$ Flood and Jackson point out (1991: 9) that "modern systems thinking was born in the biological sciences"-hence analogies with natural systems has been rooted in the tradition of systems thinking. Beer's cybemetic approach bears the mark of the attempt to regard natural and societary systems (to use Beer's terminology) as analogous. Checkland was later to launch an attack on the "hard" assumption that the natural and social worlds could be studied using the same methodological principles (cf. 1981, p. 69).
} 
36), he argues that "it does appear that the VSM has sufficient generality to justify its origin as an attempt to discover how systems are viable; and that it also generates considerable power to describe and predict, diagnose and prescribe" (1989, p. 36). In this way, Beer suggests that his pronouncements can be regarded as scientific in the sense that they have the power to describe (laws existing in reality), to predict (that if organisations do not heed the principles of viability, they will be in danger of not surviving), to diagnose (dysfunctional aspects of an existing organisation), and to prescribe (recommendations about how the structure needs to be designed if viability is desired).

Of course, Beer is relying on a particular criterion of what constitutes good scientific practice and an attendant conception of the way in which scientific pronouncements may relate to social action. For Beer, science strives to discover laws which can be used as a basis for prediction and concomitantly as a basis for making recommendations (based on the idea that people will wish to avoid undesirable outcomes that science predicts to ensue when/if certain conditions are present). Beer believes that the laws on which his model of the VSM are based, do exist, or rather, that there is a strong chance that they do indeed exist because scientific statements referring to their existence have predictive and diagnostic power. Beer claims that "predictions" that he has made about which organisations will and won't survive, provide strong evidence of the existence of the laws on which the predictions are based. What Beer does not account for is that these "occurrences" are interpreted from the cybernetic framework which grants (hypothetical) status to these laws. There is thus already some predisposition to view the occurrences in a particular way. Other "observers" may well provide alternative explanations of successful versus unsuccessful organisations, based on other factors, which they deem relevant and which do not include reference to Beer's laws. Indeed many practitioners-such as those in the "soft" camp-have argued that Beer's explanations can be replaced by others, which are as (or more) "powerful" in grasping features of social existence. [Compare Jackson (1989, p. 428) and Gregory (1992, p. 50) for a discussion of this aspect of soft systems thinking.] The fact that Beer's discovered laws would not be agreed to exist within some camps (which, too, consider themselves as scientifically credible) means that, at the least, propositions conceming their supposed existence must remain tentative. The implications of this are discussed more fully in the section below which deals with Espejo and Harnden's argument.

The danger of Beer's approach-and his appeal to the "science of effective organisation" -is that it requires of "participants" (as he calls them) to accept this cybernetic vision of "what really is a viable system." Already by "seeing" the laws of viability and using this as a basis for diagnosing the "real" faults in particular systems, Beer is directing people to consider that the viability of the organisation may be at risk unless they heed his accounts. People may come to see as imperative the redesign of the structure in accordance with his dictates- 
or rather they are faced with the option of listening to his suggestions or failing to survive organisationally. So they then may decide (perhaps unnecessarily if the laws do not exist, which is, at the least, uncertain) to submit to a structure as envisaged by Beer as viable.

This submission may affect people differently placed in the organisation in different ways-it may indeed be a means whereby those involved in "higher management" can plead to the workforce to submit to their dictates on the grounds that this is essential for viability. It may be a way in which voices of dissenters become marginalised on the grounds that they are being "unrealistic" (in terms of the reality of the laws as "seen"'/known by Beer). Beer himself argues that "higher management" in an organisation is not equatable with "top management" (1981, p. 277) and that people from any position in an organisation may enter the arena of higher management decisions. [These refer to decisions taking place in his so-called Systems Three, Four, and Five of the system under consideration, that is, the (sub)systems concerned with control, strategy and policy.] Nevertheless, it must be conceded that Beer is not recommending that all persons involved in Levels One and Two of the system [that is, the (sub)systems involved in implementation and the co-ordination of implementation] are directly represented in the decision-making of "higher management." Indeed it is unlikely that in terms of the model it is expected/supposed that everybody will be thus involved. This means that ultimately a design which requires of Levels One and Two to support the commands generated by "higher management" can become a coercive force in an organisation. This is especially so if the design is presented as one based on "laws" of viability and hence not challengeable by "lay" people having little (or no) scientific knowledge about these laws.

Beer feels that the proper application of his VSM model should not result in unnecessary coercion because it is premised specifically on allowing the highest possible degree of autonomy to subsystems (parts of the larger system which themselves should be seen as viable systems in terms of the principle of recursion). He argues that "autonomy turns out to mean the maximum discretionary action for any part short of threatening the integrity of the whole"" (1992, p. 7). He argues that a system is not viable if its design fails to grant maximum discretion at the "on-site" level. The problem with this pronouncement is that, again, "maximum discretion" comes to be defined by scientists or experts having a knowledge of the VSM-rather than by those whose "discretion" is at stake. Jackson points to the problem associated with this aspect of the VSM: "Once some limitation on the autonomy of the parts is accepted, the question immediately arises as to the basis on which this can be justified" (1989, p. 434). Jackson's question is relevant if we decide to concentrate on the moral aspect of the practical interventions implied by the theory.

Beer $(1992$, p. 7) cites his work in Chile as an example of the way in which "proper autonomy" of parts of the system can be ensured. But there are 
aspects of his own account of the application in Chile which can be disturbing when one considers their moral implications. For instance, he argues that if a "System One" is in trouble, it may try to get itself out of it (within a reasonable time period) or failing this, it may send an "algedonic signal for help" (through to the higher levels of management) $(1981$, p. 275). However, Beer suggests that the model also takes account of the fact that System One may be "too cocksure, or too lazy, or too corrupt to mention its problem. . . ." (1981, p. 275). In this case the System One will have to be alerted (from above) to the fact that it has a problem which is causing lack of organisational integration. ${ }^{3}$ Beer feels that his model is morally fair because "it is not difficult to persuade people that their best interest is served by automatic notification of their difficulties-provided they themselves have control over the parameters of the system in which this will be done'" $(1981$, p. 276). But this is the crux of the moral problem: Beer is using the force of science to persuade people to accept certain features of the functioning of a viable system. It may indeed not be difficult thus to persuade people. But perhaps if the interaction was one in which the perspective of participants was granted equal status in the discussions about the way decision-making should take place, people would not allow themselves to be thus "persuaded." Beer argues that in any case the firing of signals will be rare "if all concemed do their agreed jobs properly" (1981, p. 276). This begs the question as to whether they agreed to do their jobs within particular parameters because this appeared to them in the guise of a scientific pronouncementrather than a negotiable construct.

Beer's realism accepts that there will be rules that will have to be made in any organisation and that people must submit to these in the interests of the viability of the enterprise. He accepts that commands can be sent downwards from System Three [via the command axis $(1981$, p. 175)] invoking the authority of System Five. Although he admits that System Five may encompass many viewpoints he also suggests that "the boss" in consultation with a management team is likely to make a decision which will probably be "right" (1981, p. 206). (Other) participants within the organisation may accept that this all is necessary for the smooth functioning of the system. The question about whether the interests of some, rather than others, are served by the rules is left unposed. Rules which govern people's activities only make sense in the light of the overall purposes of the organisation-and Beer does not refer to a mechanism by which such purposes may be decided (cf. Jackson, 1989, p. 435). Although he argues that policy-making will reflect general interests if the organisation is viable, the interpretation of this rests on the idea that if the boss, with certain others,

\footnotetext{
${ }^{3}$ Ulrich offers a critique of this aspect of Beer's argument on the grounds that there is an asymmetry in the direction of control: Systems Three, Four, and Five are not required to send signals for "help" (1983, p. 365).
} 
deliberate together, then the "management group will . . hardly ever make a mistake" (1981, p. 207). [Assuming, too, that messages can be received by the boss "from the next stage down" 1981, p. 206) and that senior managers also receive messages from their subordinates.]

Now, of course, if this legitimacy of decision-making structures becomes accepted in an organisation, then it will become so structured. The management team-with the boss as arbiter-will make decisions and these may be "accepted" in the organisation and acted upon. Does this mean the science of organisation was useful? Or was it too useful and perhaps based on too much of a reliance on science? In considering the issue of the way in which modes of operating in society may become legitimised, Gouldner points out (1971, p. 293) that people who "accept" particular structural arrangements may do so in order to preserve their own sense of dignity. He argues, "Those who obey because they are afraid, do not like to think of themselves as . . cowardly; in an effort to maintain a decent regard for themselves, the fearful frequently find ingenious ways in which they can define almost any demand upon themselves as legitimate" (1971, p. 293). So people's "acceptance" of the persuasions which are brought to bear upon them (and which are bolstered by an appeal to what is "necessary" for structural integration), does not preclude the possibility of a forced consensus. Indeed this paper argues that such a possibility is more likely to the extent that the proposed structural arrangements are presented as scientifically grounded with reference to real laws (rather than intersubjectively negotiable).

Summarily presented, Beer's assertions are based on the following view of the way in which scientific knowledge relates to reality:

Statements about laws ('tested" as far as possible through the rigours of scientific inquiry) are aimed at offering a picture of real laws in the (natural and social) world.

The scientific basis provides the framework for making accessible (via the VSM) the findings of science to social participants.

This paper wishes to assert an alternative view:

Statements about laws $=$ Constructions which are open to debate in forums which include input from participants in society concerning their relevance.

This altemative view of the way in which scientific statements may be "applied" in society is offered by Espejo and Harnden (in the context of discussing the status of the statements on which the VSM is grounded). The next section spells out and offers an elaboration of their argument. 


\section{AN ALTERNATIVE VISION OF THE VSM: RAUL ESPEJO AND ROGER HARNDEN}

Espejo and Harnden have attempted to defend the utility of the VSM on the grounds that its logical coherence does not imply that it has to be used in any specific way to make design prescriptions for organisations. They note, "Formally speaking, the VSM is a set of logically coherent abstract ideas that may be interpreted and used very differently by different people" (1989, p. 453). According to them, all that the VSM is prescriptive of is "the need to have the participation of multiple viewpoints in order for the complexity of a social enterprise to be at least partly expressed"' $(1989$, p. 453$)$. As they see it, the VSM may be interpreted as a guideline which can be used to "support conversations and co-ordinate activities in the organisation." The VSM then may be used to support conversation and coordination in ways which allows participants to contribute to the discussion as to how the complexity should be approached. For Espejo and Harnden, the model can be used in a way which "is generative of collaborative linguistic interactions ..." $(1989$, p. 452). Interestingly (for the argument in this paper) Espejo and Harnden accept that the use of the methodology does not commit the user to any truth or objectivity claims $(1989$, p. 456). This means that the VSM model may become presented to participants as a construct to help guide discussion about organisation-rather than as a model grounded in knowledge of (truth concerning) the realities of effective organisation. Nevertheless, Espejo and Harnden still refer to the notion of the "generative power of science and any related methodologies, in order to coherently orchestrate the change that is happening anyway" $(1989$, p. 455$)$. How can this statement be interpreted in a way which is compatible with their relinquishment of claims to truth and objectivity in the use of methodologies? Their following sentence offers the key: "Scientific explanations are not simply reflections of the 'way things are and ought to be,' but are generative of hitherto unthought ways of experience and novel insights about the order of things", $(1989$, pp. 455,456$)$. In other words, Espejo and Harnden break with the view of science as proffered by Beer. For Beer the aim of science is to strive towards discovery of "the truth" about existing laws (and Beer believes that the science of cybemetics has made progress in discovering certain laws conceming effective organisation). For Espejo and Harnden science is a process of generating unthought of ideas which may provide insights to people. The insights do not claim to present the one true picture about "the order of things." Espejo and Hamden note in this regard that "it has gradually become acceptable to state the obvious-that it is just not true that there is 'one best way' of looking at social phenomena, or that we should strive towards 'the best way'" (1989, p. 452).

This does not imply a relinquishment of scientific activity-science and the ends of science come to be seen differently (from Beer's conception). Science 
involves an effort to "coherently open up the social domain to our observation"- without thereby implying that there is one way of establishing coherence for which we should strive $(1989$, p. 452$)$. What is relevant in terms of this paper is that Espejo and Harnden's epistemological position leaves more space for users of the methodology to regard their insights as guidelines for a consideration of design-rather than as prescriptions. This avoids the problem alluded to earlier in the discussion of Beer-the problem of scientific pronouncements coming to constrain the discussion unnecessarily. Beer may retort that because his model and the theory behind it gain empirical justification partly through their application, if they were unable to be successfully applied, the scientific theory would have to change. Thus Beer may argue that the scientific pronouncements are open to challenge and indeed will change according to the experience developed in their application. The problem, though, is that in the social domain an appeal to "science" (defined, as Beer does, as the science of effective organisation which should be "of use" to anyone concerned with viability) may come to constrain the discussion that takes place in the social application of the theory. Espejo and Harnden's alternative vision of the way in which science can be defined seems to leave more scope during the "application" of theory, to generate insights which themselves will add to the "hitherto unthought ways of experience and novel insights . . " (1989, p. 456).

Seen in the light of Espejo and Hamden's account of science (as discussed and interpreted above), Beer's statement that "obviously the findings of science should be made fully accessible to managers" (1985, p. $x)$ is not so obvious after all. In making them accessible, Beer seems to forget that one is not just applying "findings," but intervening in the social discussion in a specific way, that is, in a way which authorises particular conceptions.

Jackson has proposed in what he calls a "provocative" research note (1992, p. 564) that one could reassert the relevance of Beer's position in the face of Espejo and Hamden's reconstruction, because there is still the possibility that "cybernetic laws governing the viability of complex systems" do exist (in independent reality). He argues that if they do exist, then there is clearly an important role for a science of cybernetics in the social realm. Jackson is concerned with two aspects of Espejo's and Hamden's position. These are dealt with in turn.

(1) Jackson is concerned that in treating the VSM as a hermeneutic enabler, one is using the VSM in a way that seems to diminish its significance. One is assuming that the scientific reference to real (natural and social) laws is less important than the way in which people in organisations perceive their world (and perceive the relevance of the so-called "laws"). One is thus adopting the view that it is better to engage/invite social discussion concerning modes of organisation than to appeal to the authority of scientifically discerned laws as the frame of reference for (re-)organising.

In regard to the above concern of Jackson, this paper concedes that in treating the VSM as a hermeneutic enabler, one is challenging Beer's assumption 
that scientifically discerned laws are to be "made accessible" to people in order to aid "realistic" organisation. One is stepping out of the confines of Beer's self-understanding of his approach. It is suggested in this paper that it is more morally "suspect" to utilise the VSM model with Beer's self-understanding than to utilise it (as do Espejo and Harnden) as an enhancer of social discussion. This relates back to the problem of the self-fulfilling effect of authorised conceptions of "realities." Admittedly one cannot prevent "insights" of social theorists/interveners from "making a difference" to the social world of lay participants. But it is here argued that it is preferable that both the theorist/ intervener and the participants (lay theorists) treat the "insights" as "novel ways of seeing reality" instead of authorised (true or approximately true) visions thereof. It is on these grounds that this paper sides with Espejo and Hamden's view of the VSM as (in Jackson's words, 1992, p. 563) an "hermeneutic enabler" (of conversations about complex social issues).

Of course, one is taking a risk when one chooses to regard the VSM in this way. For it is still possible that the laws governing the viability of complex systems do indeed exist and that science is able to make progress in their discovery through using "correct" procedures of scientific inquiry. This being the case, and if we knew that Beer's procedures were appropriate (a contentious issue itself!), we would do well to take note of his claims, for these would be good approximations to reality by virtue of their being scientifically validated (as far as possible). But the point is that we do not know that the laws exist; nor that science (however one defines this) can proceed to offer a better or best way of grasping them. So by deciding to accept Beer's self-understanding of the VSM, one may be unnecessarily constraining the social discussion around the scientific framework.

An epistemology which allows for social participation in defining the relevance of any "discovery"/insight is aimed at specifically addressing the moral problem associated with the authorising of "scientific" pictures. It is aimed at reducing the risk-unaddressed in Beer's epistemology-of falling prey to authoritative accounts of "reality." It is this risk which is regarded as the more "catastrophic" in terms of the argument in this paper. [Romm (1991; pp. 152, 185-187) spells out this argument by referring to Habermas's "nonrealist" critique of both positivist and realist self-understandings of scientific practices.]

(2) Jackson's concern with the way in which the VSM is utilised by Espejo and Harnden raises another issue. If one decides to treat the VSM as a hermeneutic enabler, on what grounds can one argue for the use of this particular approach as opposed to the myriad of others that are already available for use or that can be designed? Once one does not accept as binding Beer's criteria for defining the scientific grounding of the VSM, the way is surely opened to consider the possibility of other modes of intervention in the social world. It 
appears that Espejo and Hamden do indeed admit this, for they state that we should harbour "an explicit recognition of the limits to the claims being made for one particular approach" (1989, p. 456). But Espejo and Harnden do not elaborate on this aspect of their argument. They do state that we might go along the "right" road by attempting to generate an "explicit and visible expression of [a] consensual territory in terms of a community of observers . . ." (1989, p. 456). Do they mean by this that such a community could be geared to consider various possible methods of intervention in social reality, including ones surpassing the VSM? And how do they propose that the consensual territory (which is to mark out the use of particular methods) will be explored, especially if we wish (as they do) to recognise that "discourse" is at the same time subject to plays of power? Although Espejo and Harnden do not elaborate on what the exploration of limits might involve, it can be said that their position opens the way for the researcher/intervener to choose not to use the VSM, if its application is considered inappropriate in a particular context.

In reflecting on the scope of application of the VSM, Jackson explicitly states that it is necessary to consider whether "other methodological approaches, such as Checkland's 'soft systems methodology' or Ulrich's 'critical systems heuristics" " fulfil requirements which at times surpass the boundaries of a VSM approach (1989, p. 434). Jackson's argument here echoes earlier statements that he has made concerning the way in which the VSM may be treated as one option amongst a variety of possible theoretical and methodological stances (cf. Jackson and Keys, 1984; Jackson, 1987; Flood and Jackson, 1991). Jackson argues that our conceptions of whether a methodological approach is appropriate for a certain context are broadened and enriched to the extent that choices of methodology are opened to critical inquiry in the face of altematives. As indicated above, it may be suggested that a reading of Beer's VSM in the way suggested by Espejo and Harnden is compatible with Jackson's proposal to utilise critical inquiry in order to explore the limits of various approaches.

It is to one alternative to the VSM that the paper now tums, by examining the theoretical premises of the use of the soft systems methodology (SSM) as defended and outlined by Checkland and Scholes. ${ }^{4}$ In offering an account of this alternative, it is at the same time argued that the way in which the theoretical propositions are presented, may come to direct practice in ways not recognised by the self-named proponents of SSM.

\footnotetext{
${ }^{4}$ It may be argued (and is implied by Jackson, 1992, p. 564) that using the VSM as a hermeneutic enabler renders it similar to the use of SSM, where ideas of relevant systems (and their modelling) may be utilised as guidelines for organisation. This means that we have to admit that the suggestions of the VSM have to be placed on a par in status with the models of human activity systems utilised in the SSM. One can nevertheless assert that the guidelines of the VSM provide a different framework for the exploration of issues of organisation than those utilised by SSM researchers and that, in any particular case of intervention, researchers, together with participants, may be required to choose between the details of the use of VSM or SSM.
} 


\section{SOFT SYSTEMS METHODOLOGY (CHECKLAND AND SCHOLES)}

Checkland's systemic approach to understanding and intervening in social reality is called a "soft" approach by virtue of his insistence that social science cannot treat its subject matter in the same way as does natural science (1981, p. 69). Checkland argues that in using systemic ideas to conceptualise social reality, we have at the same time to be aware of the "special nature of the component of the system studied by the social scientist: the component is the individual human being [who is] an active participant in the phenomena being investigated" (1981, p. 69). The distinctive feature of humans is that they attribute meanings and modify situations in potentially unique ways (1981, p. 69).

Checkland has developed and (together with Scholes) refined a methodology for intervention in the social world. This methodology is based on two major theoretical "hypotheses" (or starting points). The first is that ". . . it is useful to take the world to consist of a complex of interacting systems" (Checkland, 1981, p. 214). Checkland argues that if this hypothesis "is a good one, then this will be a good way of getting insight into the nature of the real world and its problems" (1981, p. 214). Checkland elaborates on this by suggesting that "if A exists to serve B then it cannot be considered on its own ... this applies wherever one system serves another" (1981, p. 234). Checkland has taken this idea and translated it into methodological guidelines for developing definitions of systems of human activities in conjunction with participants engaged in social interaction.

The second theoretical suggestion that Checkland advances is that "human beings can always attach different meanings to the same social acts" (1981, p. 214). Checkland argues that "the realisation of the importance of this concept [which refers to the fact that humans differ in their worldviews, or Weltanschauungl is a major outcome of the research, and is counter to the main concept of hard systems engineering" (1981, p. 215). The methodological guideline that springs from this insight is that the "good systems thinker" has to be able, when applying the methodology, to generate many alternative ways of seeing the world of interaction in which participants are engaged. The generation of what Checkland calls possible "relevant systems" is a means to draw out and explore alternative perceptions of the context of the interactions $(1981$, p. 223). Checkland admits $(1981$, p. 223) that when caught up in the intervention process, the methodologist is not striving to offer a "neutral" account of the world in which participants are engaged; but rather striving to draw out alternative perceptions, as a prelude to engender debate (at another stage in the use of the methodology). As discussed later, Checkland believes that the methodologist's drawing out of specific perceptions in particular contexts is based on a theoretical conception of social reality that has proved to be useful-this is the 
conception of social reality as characterised by alternative worldviews. Checkland seems to be arguing that in taking this conception of social reality into account, the methodologist is displaying a type of neutrality at a different level: The methodologist is drawing on a theory about humans, a theory which he or she has attempted to "test" in a "spirit of neutrality" (1993, p. 9).

Hence Checkland combines two ideas in his approach to social reality:

- The first is that insight may be gained into social reality by utilising the concept "system."

- The second is that insight is gained into social reality if we adopt a conception of humans as having the capacity to attribute differing meanings to social acts.

These ideas constitute the framework for the adoption of what Checkland calls "soft systems methodology" (cf. 1981, p. 220). Checkland argues that the engagement in and development of the methodology has helped him to confirm the notion that it was necessary to "put on different kinds of thinking caps" [from the ones being wom by the "hard" systems thinkers] (1981, p. 220).

Checkland argues that the adoption of different thinking caps was "crucially needed" (1981, p. 220). He cites favourably Popper's suggestion that it is possible to know when a new/different way of thinking is "better" than some alternative. According to Popper, Checkland notes, scientific visions are always rooted in some theoretical framework, but certain frameworks are "better and roomier" [than others] (1981, p. 220). Checkland also cites favourably the suggestion [developed by Popper (cf. Romm, 1991, pp. 28-40)] that science is "the most powerful means we have of making valid some of our intellectual constructions" and that the way in which this is done is by subjecting these constructions to "severe tests" and seeing if they survive such testing (Checkland, 1981, p. 248). Checkland adds the caution (in similar Popperian vein) that our constructs should not be read as "descriptions" of reality, for they are simplified constructs of reality. As Checkland puts it: "We . . need to remind ourselves that there is a distinction between complex reality and our notations of it" (1981, p. 248). Nevertheless, we have ways of knowing when certain constructs/notations tell us more about reality than others. Checkland suggests in this respect that "the model [notation] of social reality implicit in the [SSM] methodology is a well-tested one" (1981, p. 265).

In the book Soft Systems Methodology in Action (1990), Checkland and Scholes are at pains to show that they make a distinction between using the term "system" and believing that this construct refers to something "in reality." They note that systems thinking, generally speaking, is about using systemic ideas consciously to interpret the world, that is, to conceptualise the perceived world (perceived by the thinker) as a system $(1990$, p. 20$)$. This means that one chooses to treat the world as if it can be described as "a whole with emergent 
properties, a layered structure and processes which enable it to adapt to environmental pressures" (1990, p. 21). Checkland and Scholes explain that when they use the word "system" in systems thinking it is not meant to have referential status in the sense of being a label for "things" in the world. It is a concept which is used to indicate a possible way of approaching reality. They define holonic thinking as thinking with wholes, or making use of the concept of the whole in order to spark off a process of understanding the world.

In considering their epistemological position in relation to that of "hard" systems thinking, they emphasise that what distinguishes their soft approach is that they do not claim that the world itself contains holons: They claim only that holon is a useful conceptual device which aids our understanding. They thus criticise hard systems approaches epistemologically on the grounds that "hard systems thinking assumes that the perceived world contains holons" [while soft systems thinking does not] $(1990$, p. 22). They also distinguish their approach on the grounds that it explicitly recognises that people's purposes and experiences (within networks of social interaction) may differ. They point out that soft systems thinking was developed to cope with situations "in which the people in a problem situation perceive and interpret the world in their own ways and make judgements about it using standards and values which may not be shared by others"' (1990, p. xiii). Here Checkland and Scholes reiterate the point that the concept of humans as differing in their worldviews is a useful and fruitful theoretical conception to adopt.

How can we treat the various statements made by Checkland and Scholes in order to glean the epistemology that seems to underly their argument?

It must be pointed out that despite their caution to treat (systemic) constructions as devices that aid understanding (rather than as descriptions), they do believe that their theoretical constructions and concepts offer us some insight into social reality. They argue that the methodology that they have developed, is meant to be "a very practical use of systems thinking [in relation to the social world] . . one which is soundly based theoretically" (1990, p. xiv). When they claim that their methodological approach is based on a sound theory, they seem to mean (based on Checkland's remarks cited above) that the theory has been tested in a way which leads us to regard its constructions as "better," in the Popperian sense of having more truth-content than others. [Compare Romm (1991, p. 33) for an account of the Popperian view of this.] It should be noted that while Checkland accepts much of the Popperian view concerning the need for the testing of theory (and concerning the idea that we can make progress in developing "better" theoretical frameworks), the two authors differ in their view of the methodological unity of the natural and social sciences. While Popper contends that such unity is possible, Checkland prefers the phenomenological view of their disunity. The phenomenological view, in the way that Checkland treats it, is still compatible with the suggestion that science should strive to attain increased understanding. Checkland argues that the successful 
application of "soft" methods of intervention provides some "justification," for the view/image of social reality on which the methods are premised (1981, p. 277).

Checkland and Scholes indeed suggest that the practical experience gained from applying the soft systems methodology (SSM) itself feeds back into the theoretical vision of reality -this is part of the empirical grounding/testing of their body of theory. Hence, Checkland and Scholes often point to the "interaction between theory and practice" (cf. Checkland, 1993, p. 8). Checkland and Scholes state their argument as follows: "Theory must be tested out in practice and practice is the best source of theory. The book recounts some experiences in trying to move around this cycle" (1990, p. xiv).

Checkland insists that the process of developing systemic inquiry should be "done in the neutral spirit which the logic of scientific inquiry calls for" (1993, p. 9). What Checkland appears to mean by this is that the theoretical concepts employed by (scientific) systemic inquirers should strive to offer an understanding of "reality"- an understanding which as far as possible is untarnished by the taint of subjective (or even intersubjective) points of view. Checkland argues that while the theoretical position he has come to adopt (and which grounds his methodology) may not be "totally objective," it at least constitutes "well tested substantive knowledge about the area of application of the methodology-namely social reality" (1981; p. 254 ; my italics). ${ }^{5}$

Checkland and Scholes point out that the aim of using their methodology is to "initiate and orchestrate the debate about purposeful change" (1990, p. 7). (This is achieved through a specific stage in the methodology, in which the exploration of relevant human activity systems is compared with "perceptions of the world" which participants in social situations might have.) The aim to orchestrate debate about purposeful change is based on the theoretical recognition that people may differ in their interpretations and judgements about what is possible and desirable.

While Checkland and Scholes believe that their interventions are based on a sound theory, and that their practical methodology may help to validate the theory, they fail to consider that their "understanding" already gears practical

\footnotetext{
${ }^{5}$ One of the reasons why it is difficult to see what Checkland and Scholes mean by stating that the methodology is based on sound theoretical knowledge is that there appears to be little substance in the theory, apart from the two main ideas elucidated above. Nevertheless, it seems that they wish to argue that they could not have developed the methodology without some theoretical account of "system," and of the relations between people in social reality. Their conception of power and politics (elucidated below) can also be regarded as part of their theory. The focus of their argument, though, has been more on developing a methodology for intervention, so that "systerns of purposeful activity" can be outlined in the course of acting within the perceived "problem situation" (cf. Checkland, 1989, p. 40). Checkland at times verges on arguing that "intervention" is the prime concern. But at other times he insists that systemic inquiry is geared towards understanding of, as well as intervention in, social reality and that the scientific development of a body of social theory is a necessary accompaniment to intervention (cf. 1993, p. 9).
} 
activity in a certain direction, and excludes other options for action. Their "sound theorising" already expresses the intention of a particular type of intervention in social reality. Although they argue $(1990$, p. 7$)$ that the methodology should not be used rigidly, for it is there to help in the face of life's richness and not to constrain, there is a point at which the methodology seems to involve an unacknowledged constraint. Their decision to view the world in a way which suggests that debate can be initiated between participants engaged in purposeful activity already directs participants towards activities in which they tend to look for ways of communicating with others-hoping to achieve agreements (if only working agreements) or accommodation of interests.

To say that systems thinking about purposeful activity can be tested with reference to "practice" is to forget that the practice itself may have been directed so that it came to fulfil the demands of the theory. For example, Checkland and Scholes themselves admit that the aim of using systems models in their methodology is to "use debate ... to define purposeful action which could improve the problem situation" (1990, p. 6). They then state that taking the action "could change the situation . . . so the process [of building models of systems of purposeful activity] begins again" (1990, p. 6). What is not recognised is that already in building models in the initial intervention one is directing the change in a certain way-towards making the participants explore the potential for dialogue, debate and/or accommodation of interest.

Jackson $(1982$, p. 25$)$ presents a similar critique, using and subverting the terms of Checkland himself: Jackson suggests that there may be no place within SSM for the analyst who wishes to proffer "radical" relevant systems (1982, p. 25). What Jackson highlights is that in the process of exploring options, radical relevant systems may easily be discarded (or indeed never introduced). Checkland and Scholes seem to presuppose that one should focus on dialogue as a means to generate feasible compromises and accommodations, using "relevant" systems as the springboard for debate.

Checkland and Scholes fail to address the possible complaint that their theoretical approach (and attendant methodology) is not used to orchestrate possibilities of direct political struggle against those who appear intransigent. Or to alert people to the possibility of resisting "the system" by, for instance, go slows, passive resistance, etc., when they feel that those "in higher levels" are, in their eyes, unreasonable and not willing to encounter alternative views.

Checkland and Scholes' vision of political action is circumscribed by their definition of politics and power. A definition which they offer is as follows: "Politics is taken to be a process by which differing interests reach accommodation. . . . Accommodating . . . interests is the business of politics" (1990, p. 50). They also suggest that if political issues are all "bluntly made public" this itself can become a commodity of power in "real" situations (1990, p. 51).

Their vision of politics means that the ensuing methodology would seem 
to direct political action into either trying to reach an accommodation of interests or in making public the power relations so as to reopen the possibility of dialogue. But this then implies that the theoretical conception of power and the way in which SSM is used tends to make an intervention in this direction. It is not a (more or less "objective" or neutral) theory about human purposeful activity which is attaining an application. The theory already (ideologically) both presupposes and directs certain applications/interventions-those in keeping with the requirement to attempt to solve issues though debate. Although Checkland wishes to strive for ideology-free theorising (cf. 1992, p. 1029), it can be argued that his position contains ideas for action which are presupposed by the theory and which cannot be "tested" by the application of the theory. This is the import of Flood's suggestion (1993, p. 633) that despite his reference to the "testing"' of theory, Checkland is unwittingly "push[ing] an ideological position."

Checkland and Scholes cite the cases of the successful use of SSM as relevant to the scientific status of their theorising. They refer to the notion that the SSM approach is a "well established way of intervening to improve problem situations" (1990, p. xiii). But, as indicated above, this statement should be treated with caution if it is meant to buttress a theoretical position which presents itself as constructed "in the spirit of neutrality." The question which needs to be asked is whether the use of another methodology which draws on a different theory-for instance, a theory which defines the power of coercion as implying intransigence to debate-would have perhaps resulted in a different intervention and with it, perhaps, different consequences. [See, for instance, Midgley (1992) for a discussion of the way in which political campaigning may require an alternative theoretical and methodological stance.]

In response to certain theorists' (including 'lay" theorists') concem with the intransigence of coercive forces, soft systems thinkers may claim that this seeming intransigence, after all, is not "given" and can be confronted/tempered through appropriate practices-such as the practices encouraged by SSM. [Gregory $(1992$, p. 51$)$ draws attention to such a claim of soft systems thinkers, as their response to the issue of coercion.] The problem with this argument is that the theoretical position, as it stands, is already predisposed towards not treating seriously the concept of intransigence (because of the prior definition of power as capable of being confronted and tempered through dialogical efforts). Hence the theoretical position does not offer guidelines for practice when it is considered (by those experiencing themselves as "suppressed") that their "dialogical partners" are merely admitting a pseudo-dialogue.

This does not imply that the use of SSM can never treat seriously the issue of intransigence/pseudo-dialogue as has been raised above. But such use would require that SSM interveners are prepared to be circumspect about the status of the "theoretical grounding" of their interventions. Instead of clinging to the 
notion that "practice" has shown that intransigence hardly ever exists (as seems to be postulated by the theory), it would be preferable to consider this theoretical postulate itself as a construct which is able to encounter critical confrontation.

Of course it may be argued that SSM has never claimed to be as strongly theoretically directed as, for example, the VSM and that it has always refreshingly allowed for a pragmatic, nonauthoritative strain. However, as shown above, it can also be claimed that despite the seemingly nonauthoritative approach, the theoretical underpinning does incline the "action researchers" using SSM to gear practice in a certain direction. A less constraining approach may require an alternative view of the status of the theoretical basis of the SSM.

Summarily presented, Checkland and Scholes' argument (as it has been interpreted above) is as follows:

Theoretical conceptions of social reality, developed by scientists through a theory/practice testing cycle, are aimed at providing an understanding of processes/features of human living together in society.

\section{A theoretical basis of "well-tested" knowledge provides guide- lines for intervention in specific contexts using SSM.}

This paper wishes to assert an alternative view:

Theoretical conceptions of scientists, like those of lay people, may constrain options for action in unreflected-upon ways. The theoretical grounding of options for action is best treated (by "scientists" and others) as "narrative" in character.

\section{Narratives $=$ constructions which define and ongoingly rede- fine options for action.}

This view of the way in which statements may be treated in society is offered by Davies, in the context of exploring (and criticising) Checkland's approach. The next section considers her argument, setting it in the context of other debates in the systems literature.

\section{AN ALTERNATIVE VISION OF THE SSM: LYNDA DAVIES}

Davies undertakes an analysis of Checkland's position and comes to the conclusion that there is no reason for systems thinkers to believe that they may gain recourse to "a truer form of reality than that which is socially created" $(1992$, p. 605). She argues that there are no grounds for assuming that the conceptions of the (soft) "scientific" theorist somehow have different status 
from the constructions created within everyday discourse; the scientific constructions cannot pretend to offer a truer version of reality than those versions offered within the discourse of reality construction in everyday life. Once we accept that the stuff of social reality is meaning-construction and interpretation (as does Checkland), the attempt to attribute a scientific status to the constructions of (soft) systems thinkers, becomes an arbitrary authority amongst the myriad of social constructions. ${ }^{6}$ The constructions of the theorist pose as if they somehow offer a truer version of "reality" and as if they may be treated as "reality," rather than as images within a constructed narrative. (Davies explicitly draws on the terminology of Baudrillard to express her argument in this respect.) Davies argues that "the narrative is all that can be found and the process of finding is one of the creation of a new narrative" (1992, p. 620). We have no means for stepping out of narratives of interpretation in order to make pronouncements about "reality". As soon as we do so, our thinking becomes ideological in the sense that it reifies images instead of inviting their critical readdressal.

She argues (1992, p. 622) that it is necessary to be able to challenge ideological dominances in the creation of narratives: She sees Checkland's epistemological stance as contributing to the creation of ideology by authorising particular theoretical concepts as "substantive knowledge" (to use Checkland's terminology). The authorised "knowledge" seems to forbid readdressal precisely because it presents itself (to itself and to others) as something known, rather than as part of an ongoing narrative of interpretation.

Davies' argument is arrived at via a critical analysis of the (soft) phenomenological position which Checkland has adopted. She carries the phenomenological epistemology to the conclusion that "reality is textual" and hence cannot be "revealed." It cannot be revealed because humans only have access to interpretations-via narratives that they construct-and we have no means of deciding that particular constructions (including the constructions of scientific theorists) present the best or "truer" version of "reality." Any method to set up criteria for deciding how to adjudicate, is itself part of a (new) narrative-which is open to critique in the face of alternatives.

As with Espejo and Harnden's position, arrived at via a reconstruction of VSM, Davies' relinquishment of the quest for the "best story" does not lead her to deny the utility of using (systemic) theorising to intervene in the social world. Her point is that the theoretical reference points should be treated as

\footnotetext{
${ }^{6}$ As pointed out in footnote 5 , it is possible to argue that there is no substance in Checkland's systemic thinking other than the way he uses (or advises the use of) concepts in actual intervention situations and in conjunction with participants. This would mean that the SSM researcher has no "scientific" status and is not attempting to base intervention on any "scientific" notions. In this reading of Checkland, Davies' and Checkland's positions would seem to coincide, at least as far as the issue of the status of concepts is concerned. However, as shown below, Davies' discussion of SSM brings to the surface questions/issues unaddressed by Checkland.
} 
"narratively real" (1992, p. 624). This opens the way for asking questions concerning "the effects of discourse in social reality creation" (1992, p. 624). Once such questions are asked, those using the SSM approach (and indeed any approach) will be sensitive to a consideration of how meaningful the approach is to all the "discoursers" (involved in the conversation about its utility). That is, its relevance will have to be subjected to critical reflection in conjunction with participants involved and affected by its use. The way in which the approach is used will depend on the way it is treated as relevant. This allows more opportunity for the "users" (and those affected) to use it in ways that may surpass the original intention of its creators and in ways which may more readily invite reconstruction of the theoretical basis.

In addition, the approach may also be treated as irrelevant (or less relevant than another alternative), even in cases where its creators themselves might have considered it as still relevant. Despite Checkland and Scholes' suggestions that SSM remains relevant in contexts of (apparent) disparities of power (because commodities of power can shift in social relationships), it may be argued, for example, that rigid intransigence on the part of some to enter a social dialogue, requires us to consider the option to employ an alternative methodologydesigned to address this issue. In any case, as Davies points out, the theoretical constraints that constrain (SSM) practice need to be "surfaced"/considered-as a prelude to be able to explore alternatives (1992, p. 625). Davies' point in this respect echoes Jackson's similar concerns $(1982,1987)$.

It must be born in mind that in terms of the argument being put forward in this paper, the degree of "real" intransigence of actors in society can never be "known." If one adopts, say, a critical systems heuristics method (as an alternative to SSM) on the grounds that it appears that quests for dialogue would be (or would continue to be) reduced to pseudo-dialogue, one cannot know that use of (or continued use of) SSM would "really" have been fruitless. Indeed the use of (or continued use of) SSM may have brought into dialogue the interests which appeared to be based on irresolvable and unnegotiable conflict. This could, perhaps, have been achieved by, for instance, alerting apparently disadvantaged participants (within a "modified" SSM approach) to sources of power/resources to which they may have access and which may allow them to feel equipped to participate more powerfully in the dialogue/negotiation.

The decision (in a particular context) to challenge the relevance of an SSM approach and introduce a different methodological stance must be recognised to be based on a perception of likely (rather than certain) consequences which were deemed to ensue from the use of SSM.

Davies points out that the challenger of any theory and methodology cannot herself/himself claim to have escaped the trap of being caught in an ideological position (in the sense of being an "impartial" observer and interpreter). Nevertheless this does not lead her to suggest that "inquiry" is impossible. She argues that it is possible and necessary, as long as it is accompanied by "self-reflective 
critique" (1992, p. 625). This critique requires of the thinker/actor to be aware of the limitations of the interpretations that she/he is advancing and to make decisions/choices in the light of such an awareness. As Davies puts it, "Selfreflective critique is a necessary part of intellectual growth, for individuals and for disciplines"' (1992, p. 625).

By introducing the notion of self-reflection Davies' argument to some extent concurs with Flood and Jackson's call (1991, p. 243) for the demise of "nonreflective" practice. Jackson argues indeed that it is by aiding self-reflection that social theory can best contribute to operational research practice. As he states, "It is necessary . . . for operational researchers to learn more about and to consider some social scientific schemata in order that they can be more selfreflective about what they are trying to do" (1993a, p. 569). Jackson proposes that critical self-reflection may lead OR researchers to be more careful in their decisions as to where to apply the range of possible methodologies. He argues, "Each approach will be useful in certain defined areas and should only be used in the circumstances where it applies best" (1993a, p. 575). It is not clear whether Jackson would concede that self-reflection requires researchers to recognise that their interpretation of "circumstances" is indeed an interpretation. For Davies this is necessary in order to prevent the narrative which defines "correctness" of use from seducing us into believing in its self-evident applicability (or even in an applicability which is "testable" with reference to some universally accepted criterion). Midgley refers to the importance of bearing this in mind when he emphasises the perceptions of the contexts in which methodologies are employed $(1988,1989,1990)$. He reminds us that "visions" of contexts are not impersonal and he suggests indeed that an explicit focus on the viewpoint "of the individual researcher in determining [guiding] methodology choice and influencing outcomes is one of the key features defining Critical Systems"' $(1989$, p. 265). Jackson appears to admit this aspect when he states (1993b) that it is not possible to decide "whether the issues or problems or systems of concern are "in the world" or whether they are in the minds of those conducting and participating in the analysis" (1993b, p. 292). Here he adopts an agnostic position in regard to the status of the "understanding" which leads us to intervene in the world in a certain way.

It is also not clear to what extent Flood and Jackson's critical self-reflective approach (1991, p. 243) makes provision for conversation/challenge between methodologies (and underlying theories), so that these may become "enriched" through their confrontation with "the other." Romm has indicated (1990, p. 20 ) how Gouldner's approach to confrontation between methodologies may constitute a mechanism for mutual enrichment. This is by each alternative being used to "provide a perspective on the other" (1990, p. 20). In Davies' terms, this confrontation would seem to be one way of "continually reconstructing the text" (1992, p. 621). Gregory (1992, p. 459) argues that Flood and Jackson's complementarism (which admits alternative theories and methodologies with 
different scopes of application) does not pay sufficient attention to the possibility of confrontation between positions. She suggests that their complementarism slips into the belief that each methodological position may be adopted "as is" provided it is used in its own appropriate territory. However, Flood and Jackson's argument could be (re)interpreted to imply that positions do have to reflect on their own limitations in the light of inputs from alternatives, springing from other theories and from participants (lay theorists) in society. This could mean that the reflection may lead to a modification of the use of the method, by the proponent being prepared to admit (some of) the "news" offered by "the other."

Whether or not Flood and Jackson are seen as making provision for this component of critical self-reflection (as is implicit in Davies' argument), this paper treats theorising and acting as rooted in an acceptance of limitation, an acceptance of the need to open oneself to "bad news" (news springing from opposing positions), and an acceptance of the continued partiality (and hence fragility) of any position adopted. [The phrase "bad news" is borrowed from Gouldner (1980, p. 18), who links reflexivity with the ability to hear and remember such news. Churchman has offered (1979, pp. 114-116) a similar conception to that of Gouldner (and others) by referring to a dialectic of thought in which ongoing opposition between ideas is a route towards continued reflection on one's position. As Churchman puts it $(1979$, p. 116), the best way to question a Weltanschauung (worldview) is to "design a powerful opposite."]

Interestingly, Ulrich, in exploring and extending the work of Churchman, Habermas, and others, has offered a theory and attendant heuristic method for social planning based on the principle of inevitable partiality (which he defines as lack of comprehensiveness). Ulrich's specific argument on this score is presented in the next section, with a view to considering its epistemological underpinning. In considering his nonobjectivist position, it is suggested that his argument requires elaboration, so that the fragility of claims to validity are ongoingly recognised, both by researchers and by (all) those involved in and affected by purposeful systems planning.

\section{ULRICH'S CRITICAL SYSTEMS HEURISTICS}

Ulrich's critical systems heuristics (CSH) is intended to offer a method of intervention in social reality which explicitly calls attention to the plight of the socially disadvantaged. He argues that it is essential that any purposively designed system should be "responsive to the needs of the socially disadvantaged" (1983, p. 37). Ulrich refers to this requirement because he believes that more often than not in society the voices of the disadvantaged are either ignored in processes of social planning or, if heard, are incorporated only within a pseudo-dialogue in which the voices of the elites are still given more weight (1983, p. 149).

Ulrich takes as his theoretical starting point the idea that "it will always be a minority of citizens that can be moved 'with reason' to follow Habermas' 
appeal to the partiality for reason' (1983, p. 151). He suggests that although it seems worthwhile to appeal (as does Habermas) to the ideal of "reason" in which all voices are granted equal status in the social conversation about social purposes, the ideal of such rationality is not necessarily shared amongst people in society. Specifically, Ulrich believes that only a "minority of citizens" will be moved by this ideal. Despite this lack of sharedness to which Ulrich points, he argues that Habermas's concern with reason (and reasoned debate) is still useful, for

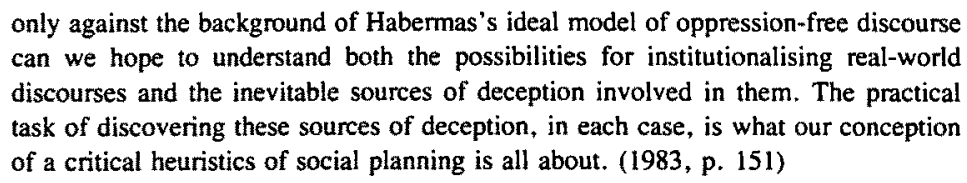

Ulrich refers $(1983$, p. 150$)$ to the possibility of a pseudo-rationality in which people in powerful positions use the force of their position to refer to an apparent generalisation of interest in terms of "the common good," "the public interest," etc., or where pseudo-compromises are made which already contain in them the failure of reason (resulting from disparities in social position of those involved in the "debate").

In the light of the problem of irrationality (defined as the suppression of voices in society due to the inequality of social position), Ulrich insists that social plans/designs need to be assessed by considering the degree of their failure/success in incorporating genuine rationality. He argues that such an inquiry/assessment must require of any purposeful system/plan that it be "selfreflective with respect to its normative implications, seen from the point of view not only of the involved [planners] but also of the affected [those who may be affected by the design]" (1983, p. 334). Any inquiry (and consequent intervention) must be guided by the question as to "whether a system $S$ is adequately designed to become a purposeful system" (as defined above) (1983, p. 334).

Ulrich (1983, p. 49) suggests that when engaging in social planning, the ideal situation would be one in which everybody's interests can be served in a process of reaching what Habermas calls a "generalisability of interests." In this case, the ideal "client" to whom the researcher is accountable would be "identical with "everybody" " (1983, p. 393). This would be in order to generate plans which serve everybody's needs. But Ulrich argues that this is practically impossible to implement because "any plan inevitably has redistributive effects (some benefit, others pay). . . . If those who most urgently need support are to get significant help, we must accept the fact that not everybody can equally benefit."

Ulrich proceeds to argue that if everyone cannot be served equally, the next best scenario would be one in which it was possible to direct planning towards a needy client without "hurting other community members"- then one 
may be able to "serve everybody but not to the same extent" (1983, p. 393). However, he also points out that when there is a conflict of interests, then the planner is required (in terms of a critical heuristic approach) to identify with the disadvantaged as the "key client." Thus he notes that in order to deal with situations where "there is an inevitable conflict among client groups, our ideal client map (ideal purpose map) stipulates as chief clients those who are the most disadvantaged in broader societal terms"' $(1983$, p. 393). Ulrich points out that in such cases, the key clients whose position will be taken into account are "those who suffer the most from the poor quality of life which societal conditions impose on them-the poor, the old, the uneducated, the working class, the unemployed, the unemployables"' $(1983$, p. 393).

In terms of Ulrich's scheme it is accepted that "there is no such thing as a plan without redistributive, i.e., politically relevant impacts" (1983, p. 394). Hence for him politics has to be taken into account as a process in which some may lose and others may win. The aim of the intervention is to ensure that those who are already "disadvantaged" are able to "win" something from the planned action.

Ulrich's theoretical underpinning for intervention differs (to some degree) from that of Checkland. Ulrich is more inclined to accept that "debate," in order to attempt to "accommodate interests" (to use Checkland's terminology), may not be the route to serving the socially disadvantaged-because this may involve them in pseudo-compromises with those who pretend to be talking to them but who indeed are their opponents. In dealing with situations in which "the elites" appear not to be "responsible to the general public," Ulrich hopes that strategies may be created to deal with elite unresponsiveness. In the context of discussing the health care system, he suggests three such strategies:

- The first is to attempt to build in structural conflicts of interest within "the elite" itself (1983, p. 404).

- The second is to attempt to "raise their consciousness" (through a process of education) (1983, p. 405).

- The third is to "make the elite accountable"-for example, through some sort of "electoral mechanism," coupled with an indication of "what will happen if they fail to obey" (1983, p. 404).

These strategies are meant to cater for a situation where "the nonelites" may wish to apply pressure-which may or may not include continued conversation with "the elites."

\section{RECONSIDERATION/ELABORATION OF ULRICH'S POSITION}

Ulrich's argument amounts to the suggestion that a critical heuristic approach offers guidelines as to the kinds of questions that researchers (and hopefully planners) should ask in order to prevent their own (limited) under- 
standing from holding undue sway. In cases where planners seem reluctant to engage in such self-reflection (as a prelude to the engagement in communicative rationality), Ulrich seems to take the position that it is normally the elites who require "consciousness raising" (education) and/or the application of other forms of pressure so that social planning will become "fairer." He does nevertheless allude to the idea that all positions have to be interrogated with a view to addressing their limitations-this would seem to include the positions of the nonelites. [Compare 1985 (p. 875), where he draws on Churchman's suggestions in order to point to the general need to treat our enemies as the mirror of our failure to be comprehensive.] But he does not offer strategies for allowing nonelites to reflect on the lack of comprehensiveness of the viewpoints they are adopting. Presumably he believes that the opposition to nonelite ideas already holds sufficient sway in society-so that the nonelites do not need to be reminded of the limitations of their stance. Nevertheless, in order to lend credence to his suggestion that all should be willing to embrance the position of "the enemy" (1985, p. 875), Ulrich would do well to suggest for all participants processes of effecting "consciousness raising" in the sense of developing an openness of consciousness to confrontation with "bad news." Instead, his focus appears to be on "educating" (as he puts it) the elite. McKay and Romm, drawing on Paulo Freire's argument concerning conscientisation, offer an account of how critical education may include a wider agenda which skills people for cognitive participation in the formulation and implementation of projects (1992, p. 150). They argue, furthermore, that the appeal to "democracy" (what Ulrich refers to as electoral mechanisms) without the skilling in critical consciousness on the part of all participants, is unlikely to lead to more dialogical forms of planning (1992, p. 155). Ulrich's concept of "education" needs to include some account of the dialectic between the affirmation and interrogation of all alternative viewpoints in society. [Gregory, Romm, and Walsh recently executed a study on National Health Service quality systems in a region of the United Kingdom, in which the CSH approach was used (in modified form?) to generate such education encounters, in peer and multi-agency group settings. Research-andintervention in the project is shortly to be "accounted for" in a report. $\left.{ }^{7}\right]$

Apart from the apparent one-sidedness of his "educative" endeavours, Ulrich's position comes dangerously close at certain points to the objectivist

\footnotetext{
${ }^{7}$ Gregory and Walsh (1993) provide a discussion of the background rationale of this study, which was initiated and set up by them. Their discussion of the way in which an arena for dialogue may be generated, draws on a reading of Habermas which highlights the ways in which agreements may be reached (1993, p. 177). As indicated below, this paper (in contrast?) calls for a reading (or extension) of Habermas so that it is explicitly recognised, by researchers and the various (other) participants, that the dialectic of confrontation is an ongoing one and that any "agreements" are fragile in character. This means that the report too should make provision as far as possible-by the way it offers "interpretations" and "recommendations" - for continued diversity of meaningconstruction.
} 
position which he is at pains to reject. For instance, Ulrich speaks about the fact that in certain circumstances (known to the researcher?), the researcher has to side with the "chief client" (the poor, the unemployed, etc.). This "fact" is in danger of passing as "knowledge" of the type that Ulrich explicitly rejects. Ulrich admits that there is no criterion in terms of which we can say that we have achieved "access" to (impartial) knowledge. Yet he seems to suggest that we do know who is "oppressed" (disadvantaged) and that we do know that in certain circumstances (of "real" conflicts of interest in society) it may be necessary to side with them and help direct them towards pressurising for change. Ulrich's pronouncements in this respect seem to go against his avowed nonobjectivist epistemological stance (1983, p. 158). Ulrich is explicit that, as he states with Flood, "there is no such thing as the 'objective' authentic interpretation of social reality as such" $(1990$, p. 19). In terms of this epistemological position, it is unclear what status he wishes to grant his reference, for example, to situations where "there is an inevitable conflict among client groups" (1983, p. 393).

Jackson argues in this regard that Ulrich at times slips into a "commonsense" materialism, which is inconsistent with his avowed epistemological nonobjectivism. Jackson contends that: "in the health planning systems example . . the material conditions that lead to particular ideas prevailing and particular designs winning acceptance ... [are] introduced by Ulrich as commonsense explanations of what is occurring"' $(1985$, p. 881$)$. Jackson argues that these explanations-which refer to "conditions" - cannot be provided within a nonobjectivist position and are indeed misplaced in such a position.

How could Ulrich respond to this charge of inconsistency? Ulrich could counter (or someone could counter on his behalf) that his "objectivation" of the situation in the process of "understanding" it, is itself based on an appeal to the discursive redemption of knowledge claims. The implications of this are explored below. But firstly it should be pointed out that the question as to whether Ulrich himself would address the issue in this way does not arise within this argument. This paper is choosing to read Ulrich's text by offering an interpretation of how a consistent epistemological stance may be achieved. This way of treating the text is admittedly one amongst possible alternatives; but it is assumed that any text inescapably requires some interpretation and that the one being advanced can be "defended." [Gouldner (1980, pp. 19-22) offers a discussion of this hermeneutic requirement.]

Returning to Ulrich's "objectivations" of "situations," this paper suggests that his insights could be seen as "checked" (thus far) in the way provided for by his (nonobjectivist) epistemology, that is, by the researcher's dialogically reflecting on other positions and taking these into account in developing categorisations which themselves are still open to discursive challenge. Romm has argued (1991, pp. 151-154) that this is indeed how Habermas's theoretical 
"insights" about society may be treated, given his epistemological nonobjectivism. 8

Ulrich could spell out such an argument (explicitly) in his example of the health care systems planning, where his apparently commonsensical appeal to "the situation" is not attended by a caution concerning the ongoing requirement for discursive challenging. It should be indicated that we cannot finally know, for example, that siding with the "chief client" in certain circumstances as identified by the researcher was/is the right course to follow. It may have been perceived as right only because of the adoption of a theory about power relations which informs the "viewing." It has to be recognised that the theory itself may predispose actors to expect that those "in powerful positions" will not be sufficiently "reasonable": Hence they may expect that they themselves will have to use force to counter the force of the advantaged. Can one really say that in the situation it is clear when there is an inevitable conflict of interests, as Ulrich puts it? The problem is that already by "knowing" that there "is" an inevitable and unnegotiable conflict of interests, one may contribute to rendering this so-through the political action which one adopts!

As with the basis for the VSM and the SSM, it is important to bear in mind the fragility of the theoretical basis of the use of CSH. A consciousness of this, enables one more readily to (re)consider, in conjunction with participants, and in conversation/confrontation with other approaches, the use and relevance of the methodology.

Ulrich himself at times recognises the above and indeed refers to such requirements. He accepts, even, that Habermas's position-which refers to the discursive redemption of validity claims-cannot provide a solid basis for offering "insights," because the ideal of discursive reason is, after all, an ideal. Ulrich accepts that Habermas's appeal to "reason" cannot practically guarantee the removal of partiality, but can only help to temper it, through providing the highest possible level of discursive checking within any social situation. It is incumbent on the knower to be aware continually of partiality, and it is incumbent on the knower as intervener to attempt to instill such an awareness in the consciousness of social participants (by requiring of them to listen to the position of "the enemy"). This, rather than an appeal to some accepted criterion for attaining "knowledge," is the best way of proceeding in the light of an acceptance of limitation.

\footnotetext{
${ }^{8}$ It may be noted in this context, that Ulrich's allegiance to, inter alia, Churchman and Habermas is a source of tension in the argument. For Churchman, the focus seems to be on an ongoing dialectic of opposition, with which we can deal appropriately only by continually "taking seriously" our confrontation with others (cf. 1974, p. 5). Habermas's position can be read as implying similar suggestions, but only if his conception of reason is interpreted to mean ongoing discursive engagement.
} 
Ulrich's position then, in the form here presented/elaborated, can be summed up as follows: The dialectic of confrontation between opposing positions is an ongoing one, which ideally should lead to (ongoing) mutual enrichment. The boundaries between different positions are not clear and can shift. This is largely because "other" positions may be used to provide alternative perspectives on one's own, which allow for a reconsideration of one's initial stance. However, this mode of confrontation requires a level of consciousness which admits some receptivity to "the other." In social life this requirement is not necessarily seen to be met. Ulrich argues that at certain points the "less powerful" may regard the opposition as impenetrable and as requiring the use of "counter-force" as a practical response to the irrationality/intransigence of the (forceful) opponent. This (practical) choice is provided for within a CSH approach, but should be recognised as an acknowledged choice (amongst alternatives) and should be accompanied by an awareness of the fragility of the theoretical "justification."

\section{FINAL NOTE}

In recognising the practical limits placed on the quest to utilise (discursive) reason, Ulrich's position can be seen as consistent with some renditions of a postmodernist position. In some renditions (cf. Flood, 1990; Leroke, 1994; Lyotard, 1990; Spaul, 1993; Taket and White, 1993; Wooliston, 1992), the point of postmodernism is to place in question any appeal to "ground" knowledge with reference to some universal criterion. In terms of this interpretation, postmodernism is at root a critique of "foundationalism," that is, of quests to discover methods for attaining knowledge. Statements about "reality" have to be regarded as narratives which are open to (ongoing) de- and reconstruction. And it is insisted that finality of "answers" can never be attained. (See also the above discussion of the similar proposals made by Davies.) Lyotard sums up the argument by stating that even where working "agreements" between participants in a social context seem to be engendered (for the purpose of continuing action) the "agreement" is a "temporary contract" "which is "subject to eventual cancellation" (1990, p. 340). Agreements reached (about "the situation" and options for action) are fragile from the start (with differences still incorporated) and hence bound to be revisited.

It is possible to consider the postmodernist critique of foundationalism as consistent with the requirement for knowers and actors to reflect on the limitations of their knowledge and on the practices attendant on this "knowledge." It has to be recognised that "theory" constrains practice in certain ways (by outlining options for appropriate action), yet at a certain point theoretical "knowledge" (however fragile) must be brought to bear in order that action may ensue. The way in which this is achieved depends on the choices that are made and the degree to which these choices reflect an awareness by actors of 
the need to have them subjected to critical confrontation. Admittedly the argument here advanced is a position which does imply some way forward in the face of the recognition of our limitations. Certain postmodernists' incredulity with "metanarratives" which provide social resolutions may seem incompatible with the appeal here to critical consciousness as a progressive force. But it must be remembered that even the incredulity with metanarratives is itself the adoption of a (meta) position and that such a position may be extended/revisited. This being so, postmodernist beliefs (positions) concerning the adversarial, nonconsensual character of language may be "extended" to include some allegiance to the notion of critical self-reflection (combined with narrative de- and reconstruction).

\section{CONCLUSION}

By critically exploring the use of various systems methods of intervention, this paper is offered as an interjection to contribute to an increase in levels of awareness concerning the ways in which theoretical positions may come to constrain systems practice. This, it is hoped, has been achieved (to some degree) by locating points at which interventions may have been unwittingly constrained by the belief in the "soundness" of the prior theory-soundness having been defined with reference to some criterion which was left unaddressed. Or rather, the criteria (sometimes different ones used by different stances) seemed to be invoked as obvious ones for validating the theoretical claims being made. The paper tried to show the possible interventionist implications-with reference to VSM, SSM, and CSH-of failing to keep in consciousness the constructed character of underlying theoretical propositions.

\section{ACKNOWLEDGMENTS}

I wish to thank Michael Jackson, Gerald Midgley, and Martin Spaul for the time they spent going through the first draft of this paper and holding discussions with me thereafter. Many of their suggestions have been incorporated, though they may not recognise or agree with the form in which these became utilised!

\section{REFERENCES}

Beer, S. (1981). Brain of the Firm, John Wiley \& Sons, Chichester.

Beer, S. (1985). Diagnosing the System for Organisations, John Wiley \& Sons, Chichester.

Beer, S. (1989). The viable system model: Its provenance, development, methodology and pathology. In Espejo, R., and Hamden, R. (eds.), The Viable System Model: Interpretations and Applications of Stafford Beer's VSM, John Wiley \& Sons, Chichester, pp. 11-37.

Beer, S. (1992). World in torment: A time whose idea must come. Presidential address, Triennial Conference of the World Organisation of Systems \& Cybernetics, New Delhi, India. 
Checkland, P. B. (1981). Systems Thinking, Systems Practice, John Wiley \& Sons, Chichester.

Checkland, P. B. (1989). Or and social science: Fundamental thoughts. In Jackson, M. C., Keys, P., and Cropper, S. A. (eds.), Operational Research and the Social Sciences, Plenum, New York, pp. 35-41.

Checkland, P. B. (1992). Systems and scholarship: The need to do better. J. Operat. Res. Soc. 43(11), 1023-1030.

Checkland, P. B. (1993). Systems science. In Stowell, F. A., West, D., and Howell, J. G. (eds.), Systems Science: Addressing Global Issues, Plenum Press, New York and London, pp. 7-10.

Checkland, P. B., and Scholes, J. (1990). Soft Systems Methodology in Action, John Wiley \& Sons, Chichester.

Churchman, C. W. (1974). Perspectives of the systems approach. Interfaces 4(4), 6-11.

Churchman, C. W. (1979). The Systems Approach and its Enemies, Basic Books, New York.

Davies, L. J. (1992). On the reality of systems. Syst. Pract. 5, 601-627.

Espejo, R., and Hamden, R. (1989). The VSM: An ongoing conversation. In Espejo, R., and Hamden, R. (eds.), The Viable System Model: Interpretations and Applications of Stafford Beer's VSM, John Wiley \& Sons, Chichester, pp. 441-460.

Flood, R. L. (1990). Liberating Systems Theory, Plenum Press, New York and London.

Flood, R. L. (1993). Checkland and scholarship: The need to do better. J. Operat. Res. Soc. 44(6), 632-633.

Flood, R. L., and Jackson, M. C. (1991). Creative Problem Solving: Total Systems Intervention, John Wiley \& Sons, Chichester.

Flood, R. L., and Ulrich, W. (1990). Testament to conversations on critical systems thinking between two systems practitioners. Syst. Pract. 3, 7-29.

Gouldner, A. W. (1971). The Coming Crisis of Western Sociology, Heinemann, London.

Gouldner, A. W. (1980). The Two Marxisms: Coniradictions and Anomalies in the Development of Theory, Macmillan, London.

Gregory, W. J. (1992). Critical Systems Thinking and Pluralism: A New Constellation, Ph.D. thesis, City University.

Gregory, W. J., and Walsh, M. P. (1993). Quality, ideology and consumer choice: Health care standards and stakeholder participation. In Malek, M., Vacani, P., Pasquinha, J., and Davey, P. (eds.), Managerial Issues in the Reformed NHS, John Wiley \& Sons, Chichester, pp. 169181 .

Jackson, M. C. (1982). The nature of soft systems thinking: The work of Churchman, Ackoff and Checkland. J. Appl. Syst. Anal. 9, 17-29.

Jackson, M. C. (1985). Book review on W. Ulrich: The itinerary of a critical approach. J. Operat. Res. Soc. 36(9), 878-881.

Jackson, M. C. (1987). New directions in management science. In Jackson, M. C., and Keys, P. (eds.), New Directions in Management Science, Gower, Aldershot, pp. 133-164.

Jackson, M. C. (1989). Evaluating the managerial significance of the VSM. In Espejo, R., and Hamden, R. (eds.), The Viable System Model: Interpretations and Applications of Stafford Beer's VSM, John Wiley \& Sons, Chichester, pp. 407-439.

Jackson, M. C. (1992). The soul of the viable system model. Syst. Pract. 5, 561-564.

Jackson, M. C. (1993a). Social theory and operational research practice. J. Operat. Res. Soc. 44(6), 563-577.

Jackson, M. C. (1993b). Don't bite my finger: Haridimos Tsoukas' critical evaluation of total systems intervention. Syst. Pract. 6, 289-294.

Jackson, M. C., and Keys, P. (1984). Towards a system of systems methodologies. J. Operat. Res. Soc. 35, 473-486.

Leroke, W. (1994). Transcending sociology: The emergence of post-modem social theory. In Romm, N. R. A., and Sarakinsky, M. (eds.), Social Theory, Lexicon, Johannesburg, pp. 366-396.

Lyotard, J.-F. (1990). The postmodern condition. In Alexander, J. C., and Seidman, S. (eds.), Culture and Society, Cambridge University Press, Cambridge, pp. 330-341. 
McKay, V. I., and Romm, N. R. A. (1992). People's Education in Theoretical Perspective, Maskew Miller Longman, Cape Town.

Midgley, G. (1988). A Systems Analysis and Evaluation of Microjob: A Vocational Rehabilitation and Information Technology, Training Centre for People with Disabilities, M.Phil thesis, City University.

Midgley, G. (1989). Critical systems: The theory and practice of partitioning methodologies. In Proceedings of the 33rd Annual Meeting of the ISSS, Edinburgh, Scotland, July 2-7.

Midgley, G. (1990). Creative methodology design. Systemist 12, 108-113.

Midgley, G. (1992). Power and languages of co-operation: A critical systems perspective. In Sistemica '92: Ira Conferencia International de Trabajo del Instituto Andino de Sistemas (IAS), Lima, Peru, Aug. 23-28.

Romm, N. R. A. (1990), Gouldner's reflexive methodological approach. In Alant, C. (ed.), Sociology and Sociery: A Humanist Profile, Southern Books, Johannesburg, pp. 13-22.

Romm, N. R. A. (1991). The Methodologies of Positivism and Marxism: A Sociological Debate, Macmillan, London.

Spaul, M. W. J. (1993). Critical systems thinking, post-modernism and the philosophy of Richard Rorty. In Stowell, F. A., West, D., and Howell, J. G. (eds.), Systems Science: Addressing Glabal Issues, Plenum Press, New York and London, pp. 149-154.

Taket, A., and White, L. (1993). After OR: An agenda for postmodemism and poststructuralism in OR. J. Operat. Res. Soc. 44(9), 867-881.

Ulrich, W. (1983). Critical Heuristics of Social Planning: A New Approach to Practical Philosophy, Paul Haupt, Bem and Stuttgart.

Ulrich, W. (1985). Book review on C. West Churchman: The way of inquiring systems. J. Operat. Res. Soc. 36, 873-6.

Wooliston, G. (1992). The Architecture and Acuity of Critical Systems Thinking, Ph.D. thesis, University of Hull, Hull, UK. 